\title{
Ecological consequences of The Acid rain
}

\author{
Dr. Sunita Bhargava ${ }^{1}$, Sharad Bhargava ${ }^{2}$ \\ ${ }^{I}$ Department of Chemistry College of Life Sciences Cancer Hospital \&Research Institute, Gwalior, M.P.India \\ ${ }^{2}$ SOS in Earth Science Jiwaji University Gwalior, M.P. India
}

\begin{abstract}
Acid rain affects each and every components of ecosystem. Acid rain also damages man-made materials and structures Acid rain is one of the most serious environmental problems emerged due to air pollution Sulphur dioxide $\left(\mathrm{SO}_{2}\right)$ and oxides of nitrogen and ozone to some extent are the primary causes of acid rain. These pollutants originate from human activities such as combustion of burnable waste, fossil fuels in thermal power plants and automobiles. These constituents interact with reactants present in the atmosphere and result into acid deposition Due to the interaction of these acids with other constituents of the atmosphere, protons are released causing increase in the soil acidity, lowering of soil pH mobilizes and leaches away nutrient cations and increases availability of toxic heavy metals. Such changes in the soil chemical characteristics reduce the soil fertility, which ultimately causes the negative impact on growth and productivity of forest trees and crop plants. Acid rain has also been reported in India. A rainfall of $\mathrm{pH} 3.5$ was reported in Mumbai. The air pollution levels are steadily rising in the metropolitan cities like Kolkata, Delhi, Mumbai. Acid rain problem in Bihar, West Bengal, Orissa and southern coastal India has been predicted to lead to infertile soil. Acid rain makes the water bodies acidic. The amphibians are also affected by acidification of water bodies .At low pH, many species of amphibians including frogs, toads and salamander are particularly sensitive. Indirect effect of acid rain on human health involves toxic heavy metals because these are liberated from soil when soil gets acidified. The most common heavy metals are $\mathrm{Al}, \mathrm{Cd}, \mathrm{Zn}, \mathrm{Pb}, \mathrm{Hg}, \mathrm{Mn}$ and Fe. These mobilized contaminants are dissolved in soil and water make their way to groundwater that is drunk by humans and contaminate the food (Fish, meat, and vegetables) eaten by humans. These heavy metals get accumulated in the body and resulted into various health problems like dry coughs, asthma, headache, eye, nose and throat irritations. Acid rain problem has been tackled to some extent in the developed world by reducing the emission of the gases causing acid rain.
\end{abstract}

Key words: Acid rain, Causes, Effects, Control, pollutants, Sulphur dioxide.

\section{Introduction}

The term "acid rain" was coined in 1872 by Robert Angus Smith ${ }^{[[]}$Though acidic rain was discovered in 1853, it was not until the late 1960s that scientists began widely observing and studying the phenomenon ${ }^{[2] " A c i d ~ r a i n " ~ i s ~ t e r m ~ r e f e r r i n g ~ t o ~ a ~ m i x t u r e ~ o f ~ d e p o s i t e d ~ m a t e r i a l ~ f r o m ~ t h e ~ a t m o s p h e r e ~ c o n t a i n i n g ~}$ higher than normal amounts of nitric and sulfuric acids. Any form of precipitation which is acidic in nature is called acid rain. The major human sources do come from the industry, transportation, and a variety of power plants. Strictly speaking these industrial amounts of nitrogen, sulfur oxides and general pollutants from the air cause a drastic increase of the acidity of the precipitation and do also harm plants, humans, and infrastructure. The precursors, or chemical forerunners, of acid rain formation result from both natural sources, such as volcanoes and decaying vegetation, and man-made sources, primarily emissions of sulfur dioxide $\left(\mathrm{SO}_{2}\right)$ and nitrogen oxides $\left(\mathrm{NO}_{\mathrm{x}}\right)$ resulting from fossil fuel combustion. $\mathrm{SO}_{2}$ and $\mathrm{NO}_{\mathrm{x}}$ come from electric power generation that relies on burning fossil fuels, like coal. 17th century by John Evelyn, who remarked upon the poor condition of the Arundel marbles ${ }^{\left[{ }^{[3]}\right.}$ Since the Industrial Revolution, emissions of sulfur dioxide and nitrogen oxides into the atmosphere have increased. ${ }^{[4][5]}$ In 1852, Robert Angus Smith was the first to show the relationship between acid rain and atmospheric pollution in Manchester, England. ${ }^{[6]}$ Canadian Harold Harvey was among the first to research a "dead" lake. Public awareness of acid rain in the U.S increased in the 1970s after The New York Times published reports from the Hubbard Brook Experimental Forest in New Hampshire of the myriad deleterious environmental effects shown to result from it. ${ }^{[7][8]}$ Acid rain occurs when these gases react in the atmosphere with water, oxygen, and other chemicals to form various acidic compounds. Burning of fossil fuels in industries and transport sector, industrialization and urbanization have led to increase in concentrations of gaseous and particulate pollutants in the atmosphere leading to air pollution ${ }^{[9[10]}$ Industrial acid rain is a substantial problem in China and Russia ${ }^{[1][12]}$ and areas downwind from them. These areas all burn sulfur-containing coal to generate heat and electricity. ${ }^{[13]}$ The problem of acid rain has not only increased with population and industrial growth, but has become more widespread. The use of tall smokestacks to reduce local pollution has contributed to the spread of acid rain by releasing gases into regional atmospheric circulation. ${ }^{[14][15]}$ Fact is that air pollution affects both humans and the nature. Most obvious are the so-called direct effects on 
human health. Results of recent research show that small particles in the air caused more than 350,000 premature deaths within the 25 countries of the European Union in 2000. Furthermore it has to be taken into consideration that there are also other air pollutants as well as indirect effects on nature and humans. Those indirect effects include effects such as toxic groundwater and corrosion of materials. Many people use so-called blinds and/or marquees, also called Markisen in German, in order to protect for instance their terrace or patio from polluted air particles.Due to drastic air pollution and the worsening of the general air quality, the climate does also get affected. If the climate gets warmer it affects a human's health. A number of researchers fear that a warmer climate in the course of a general climate change may cause more extreme weather conditions. Strictly speaking this would also lead to more injuries and deaths being caused by hurricanes, flooding as well as to property damage. Another effect resulting from a warmer climate is the spread of a variety of insect transmitted diseases such as malaria and bilharzias.

\section{Chemistry Of Acid Rain}

$\mathrm{H}_{2} \mathrm{O}(\mathrm{l})+\mathrm{CO}_{2}(\mathrm{~g})=\mathrm{H}_{2} \mathrm{CO}_{3}(\mathrm{aq})$

Carbonic acid ionizes in water to form low concentrations of carbonate and hydronium ions. $2 \mathrm{H}_{2} \mathrm{O}(\mathrm{l})+\mathrm{H}_{2} \mathrm{CO}_{3}(\mathrm{aq})=\mathrm{CO}_{3}{ }^{2-}(\mathrm{aq})+2 \mathrm{H}_{3} 0^{+}(\mathrm{aq})$

Carbonic acid is a weak acid. It brings down the $\mathrm{pH}$ of the rainwater to 6.0-5.2. With $\mathrm{pH}$ levels ranging between 6.0-5.2, rainwater is acidic, but still not dangerous. This is a reversible reaction. Sometimes, the $\mathrm{pH}$ level can even become as low as 2 . This phenomenon of acidic rainwater precipitation, is called acid rain. Rain, snow, sleet, freezing rain, hail, fog and dew are other forms of precipitation. Acid rain is a mild combination of mainly sulfuric and nitric acid. Sulfurous acid and nitrous acid are less stable and are present only in very low amounts.

Sulfuric acid and nitric acid are the main acids present in acid rain. The problem occurs when rainwater combines with gaseous oxides of sulfur, nitrogen, and phosphoric and hydrochloric acid mists. The latter two and sulfur are released into the atmosphere from automobile exhausts, industries and electric power plants Sulfuric acid is formed as follows:

1. Sulfur released into the atmosphere combines with atmospheric oxygen to form sulfur dioxide $\left(\mathrm{SO}_{2}\right)$

2. Sulfur dioxide reacts with atmospheric water to form sulfurous acid $-\mathrm{SO}_{2}(\mathrm{~g})+\mathrm{H}_{2} \mathrm{O}(\mathrm{l})=\mathrm{H}_{2} \mathrm{SO}_{3}(\mathrm{aq})$

3. Sulfurous acid is also present in acid rain.

4. Sulfur dioxide gradually oxidizes to form sulfur trioxide $\left(\mathrm{SO}_{3}\right)-2 \mathrm{SO}_{2}(\mathrm{~g})=\mathrm{O}_{2}(\mathrm{~g})=2 \mathrm{SO}_{3}(\mathrm{~g})$

5. Sulfur trioxide reacts with water to form Sulfuric acid $\left(\mathrm{H}_{2} \mathrm{SO}_{4}\right)-\mathrm{SO}_{3}(\mathrm{~g})+\mathrm{H}_{2} \mathrm{O}(\mathrm{l})=\mathrm{H}_{2} \mathrm{SO}_{4}(\mathrm{aq})$

Nitrogen forms a major part of atmospheric composition. These chemicals bring down the acid rain $\mathrm{pH}$ level to 5.6-3.5. Nitrogen dioxide $\left(\mathrm{NO}_{2}\right)$ is formed as follows:

1. Nitrogen combines with atmospheric oxygen to form nitrogen dioxide $\left(\mathrm{NO}_{2}\right)$.

2. Nitrogen dioxide reacts with water to form nitrous acid $\left(\mathrm{HNO}_{2}\right)$ and nitric acid $\left(\mathrm{HNO}_{3}\right)-2 \mathrm{NO}_{2}(\mathrm{l})+\mathrm{H}_{2} \mathrm{O}(\mathrm{l})$ $=\mathrm{HNO}_{2}(\mathrm{aq})+\mathrm{HNO}_{3}(\mathrm{aq})$

3.

\section{Wet Deposition}

\section{Types of Deposition:}

Wet deposition refers to acidic rain, fog, and snow. If the acid chemicals in the air are blown into areas where the weather is wet, the acids can fall to the ground in the form of rain, snow, fog, or mist. As this acidic water flows over and through the ground, it affects a variety of plants and animals. The strength of the effects depends on several factors, including how acidic the water is; the chemistry and buffering capacity of the soils involved; and the types of fish, trees, and other living things that rely on the water. the process of wet deposition of acidic compounds In particular, acidic deposition has adverse effects on vegetation. This is mainly due to soil acidification and the uptake of substances, which disturb the $\mathrm{pH}$ levels within plant cells that may lead to the evolution of reactive radicals ${ }^{[16]}$.

\section{Dry Deposition}

In areas where the weather is dry, the acid chemicals may become incorporated into dust or smoke and fall to the ground through dry deposition, sticking to the ground, buildings, homes, cars, and trees. Dry deposited gases and particles can be washed from these surfaces by rainstorms, leading to increased runoff. This runoff water makes the resulting mixture more acidic. About half of the acidity in the atmosphere falls back to earth through dry deposition.The incremental effects of wet and dry deposition on carbonate stone erosion due to hydrogen ion, $\mathrm{SO} 2$ and NOx were quantified by Baedecker et al. ${ }^{[17]}$. Acid deposition also occurs via dry deposition in the absence of precipitation. This can be responsible for as much as 20 to $60 \%$ of total acid deposition. ${ }^{[18]}$ This occurs when particles and gases stick to the ground, plants or other surfaces. The results suggested that approximately $30 \%$ of erosion by dissolution could be attributed to the wet deposition of hydrogen ion and the dry deposition of $\mathrm{SO} 2$ and $\mathrm{HNO} 3$. 


\section{Adverse effects of acid rain}

Following are the various adverse effects of acid rain on living organisms and infrastructure.

\section{Buildings and Monuments:}

Acid rain causes severe damage to buildings and marble statues. Acid rain reacts with the calcium carbonate $\left(\mathrm{CaCo}_{3}\right)$ to form soluble calcium hydrogen carbonate or calcium bicarbonate, Calcium bicarbonate is a powdery substance, which is easily washed away with water or more specifically, rainwater. This is the way acid rain has partly eroded many world-famous monuments and buildings like the Taj Mahal in India, St. Paul's Cathedral in London, and the Statue of Liberty in New York. High buildings made of concrete in urban areas have damaged due to exposure to cloud water with high acidity for a long time ${ }^{[19]}$. Acid precipitations with $\mathrm{pH}$ level ranging between 3.0 and 5.0 have affected the cement and concrete ${ }^{[20] .}$ Delhi Red fort and Jama Masjid are also showing signs of damage from sulphur pollution ${ }^{[21]}$. Acid rain can destroy stained glass windows in churches, bridges made of steel, and railway tracks. It corrodes metal, ruins the paint color, weakens leather and forms a crust on glass surfaces.

$\mathrm{Ca}\left(\mathrm{HCO}_{3}\right)_{2}-\mathrm{CaCO} 3+$ Acid rain $=\mathrm{Ca}\left(\mathrm{HCO}_{3}\right)_{2}(\mathrm{aq})$

\section{Trees and Plants:}

Other plants can also be damaged by acid rain, but the effect on food crops is minimized by the application of lime and fertilizers to replace lost nutrients. In cultivated areas, limestone may also be added to increase the ability of the soil to keep the $\mathrm{pH}$ stable, but this tactic is largely unusable in the case of wilderness lands. When calcium is leached from the needles of red spruce, these trees become less cold tolerant and exhibit winter injury and even death. ${ }^{[22[23]}$. Acid rain washes away important minerals from leaves and soil. Acid rain also blocks the small pores on the leaves' surface, through which they take in carbon dioxide. With improper functioning of leaves, the growth of trees gets retarded. This results in a loss of leaves, stunted growth and damaged bark. Such trees are more prone to attacks by fungi and insects. This can even result in the death of trees.

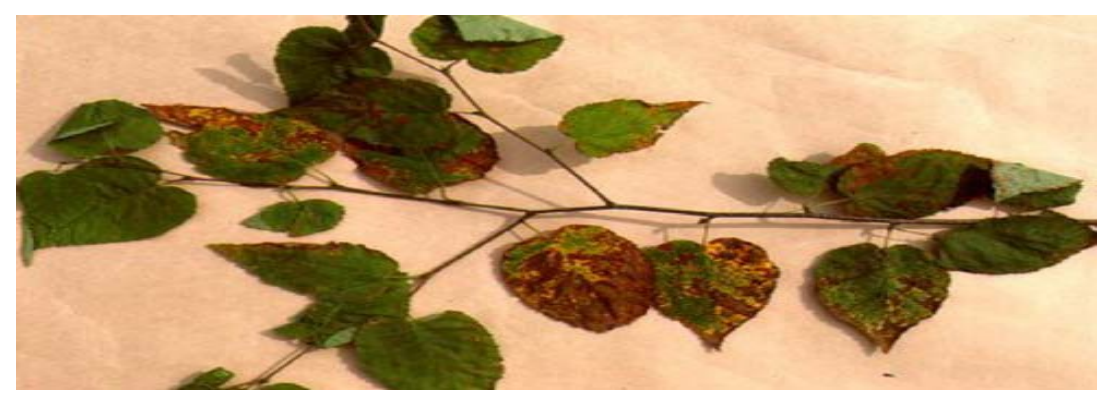

Figure 1: Damage to Birch as a Result of Acidic Fog

Soil:

Soil contains many harmful minerals such as mercury and aluminum. These elements can't be absorbed by plants and trees and are thus harmless. Upon contact with acid rain, these chemicals undergo chemical reactions with the acids. Soil chemistry can be dramatically changed when base cations, such as calcium and magnesium, are leached by acid rain thereby affecting sensitive species, such as sugar maple (Acer saccharum). ${ }^{[24][25]}$

As a result, compounds of aluminum, lead and mercury are formed. Plants and trees can easily absorb these compounds. Such elements, which are extremely harmful to living forms, ultimately affect the entire food chain. These chemicals not only harm the flora, but also the animals that feed on them. Soil biology and chemistry can be seriously damaged by acid rain. Some microbes are unable to tolerate changes to low $\mathrm{pH}$ and are killed. ${ }^{[2]}$ The enzymes of these microbes are denatured (changed in shape so they no longer function) by the acid. The hydronium ions of acid rain also mobilize toxins such as aluminium, and leach away essential nutrients and minerals such as magnesium. ${ }^{[27]}$ 


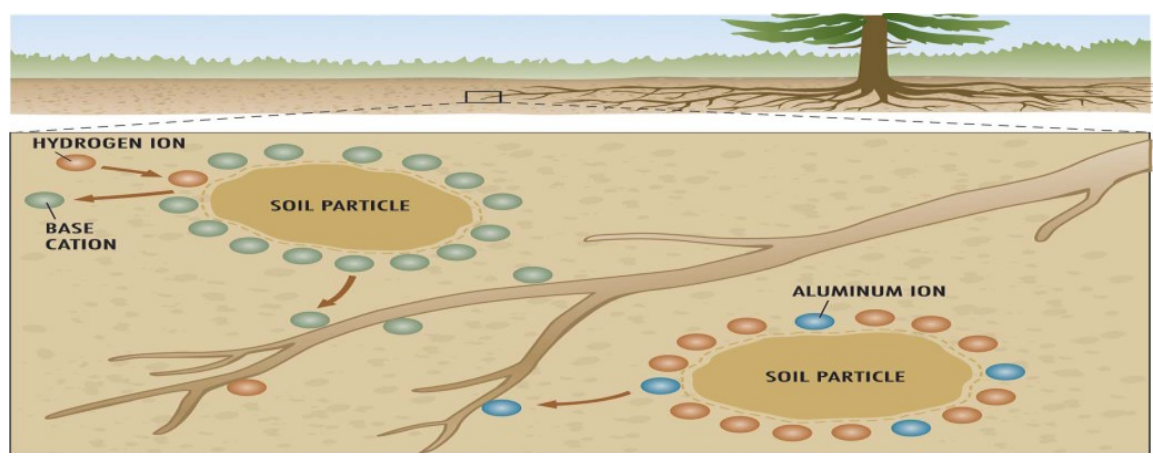

Figure 2 : Effect of Acid Rain on Soils

\section{Water Bodies:}

Harmful substances like aluminum, lead and mercury, as discussed above, are washed away from the soil to neighboring water resources by the acid rain, thus resulting in water pollution. These chemicals and their acids do not allow the flora and fauna to grow and reproduce. This also results in depletion of oxygen levels in water, thereby making it difficult for fish to respire. They die due to suffocation and poisoning caused by the presence of these chemicals. Birds that feed on fish that are affected by these harmful chemicals, accumulate these elements in their systems. These chemicals are then passed on to animals that feed on such birds. In this manner, chemicals get introduced to each trophic level of the food chain. In each trophic level, the concentration of chemicals gets multiplied. This phenomenon is known as biomagnification.

\section{Human Health:}

Acid rain looks, feels, and tastes just like clean rain. The harm to people from acid rain is not direct. The acid in the rainwater is too dilute to have direct adverse effects. However, the particulates responsible for acid rain (sulfur dioxide and nitrogen oxides) do have an adverse effect. Increased amounts of fine particulate matter in the air do contribute to heart and lung problems including asthma and bronchitis. ${ }^{[28]}$ Walking in acid rain, or even swimming in an acid lake, is no more dangerous than walking or swimming in clean water. However, the pollutants that cause acid rain-sulfur dioxide $\left(\mathrm{SO}_{2}\right)$ and nitrogen oxides $\left(\mathrm{NO}_{\mathrm{x}}\right)$ - do damage human health. These gases interact in the atmosphere to form fine sulfate and nitrate particles that can be transported long distances by winds and inhaled deep into people's lungs. Fine particles can also penetrate indoors. Acids are very small and fine particles. They are normally in a liquid state. When they are present in the atmosphere, they easily enter the lungs while breathing. Research has proven that these particles can even lead to cancer. SO2 causes more adverse impact to human health in gas and aerosol forms. Concentrations above 1.6 ppm breathing becomes detectable more difficult and eye irritation increases $\mathrm{SO} 2$ is much more toxic and damaging when combined with aerosols, and mists, and suspended smoke ${ }^{[29]}$, because these mixture of chemicals form finer suspensions that penetrate the lungs further than the gas alone. In Tokyo the polluted drizzle droplets were resulted into eye and skin irritation ${ }^{[30] .}$ Many scientific studies have identified a relationship between elevated levels of fine particles and increased illness and premature death from heart and lung disorders, such as asthma and bronchitis. Based on health concerns, $\mathrm{SO}_{2}$ and $\mathrm{NO}_{\mathrm{x}}$ have historically been regulated under the Clean Air Act, including the Acid Rain Program. Decreases in $\mathrm{NO}_{\mathrm{x}}$ emissions are also expected to have a beneficial impact on human health by reducing the nitrogen oxides available to react with volatile organic compounds and form ozone. Ozone impacts on human health include a number of morbidity and mortality risks associated with lung inflammation, including asthma and emphysema. Acid rain is harmful to human health.

\section{Table 1: Effects of Acid Rain on Water Ecosystems}

\begin{tabular}{|l|l|}
\hline As water becomes more acidic and its pH approaches & Effects of acid rain on water ecosystems \\
\hline 5.0 & $\begin{array}{l}\text { Major changes in the make-up of the plankton community occur } \\
\text { Lessdesirable species of mosses and plankton may begintoinvade. } \\
\text { The progressive loss of some fish populations is likely. }\end{array}$ \\
\hline Less than 5.0 & $\begin{array}{l}\text { The water is largely devoid of fish. The bottom is covered with } \\
\text { undecayed material. The nearshore areas may be dominated by } \\
\text { mosses. Terrestrial animals, dependent on aquatic ecosystems, are } \\
\text { affected. Waterfowl, for example, depend on aquatic organisms for } \\
\text { nourishment and nutrients. As these food sources are reduced or } \\
\text { eliminated, the sustainability quality of habitat declines and the } \\
\text { reproductive success of birds is affected. }\end{array}$ \\
\hline 6.0 & \begin{tabular}{l} 
Crustaceans, insects and some plankton species begin to disappear. \\
\hline
\end{tabular} \\
\hline
\end{tabular}


Table 2: Preferred pH tolerance for some freshwater organisms

\begin{tabular}{|l|l|}
\hline Oraganism & pH tolrance \\
\hline Fish & 6.5 \\
Flathead minnow & 5.5 to 6.5 \\
Pumpkinseed sunfish & 6.0 to 6.5 \\
Smallmouth bass & 5.5 to 6.5 \\
Brown trout & 6.0 to 5.5 \\
Rainbow trout & 5.5 to 6.5 \\
Brook trout & 5.5 to 6.5 \\
Yellow perch & \\
Frog \& toad embryos & 5.0 to 6.5 \\
American toads & 5.0 to 6.5 \\
Bullfrog & 4.5 to 6.5 \\
Woodfrog & \\
Others & 6.5 \\
Clam (some species) & 6.0 to 6.5 \\
Cray fish & 6.5 \\
Snail & 5.5 to 6.5 \\
Spotted salamander embryo & \\
\hline
\end{tabular}

\section{Solution of acid rain}

Acid rain is potent enough to destroy life on Earth. It damages anything it comes in contact with. It ruins forests, water bodies, soil, infrastructure, and the health of living beings. It's high time we take all possible measures to control it. There is a solution to every problem, and acid rain is no exception. Take a look at the various measures we can take.

- Human beings should reduce the use of fossil fuels. This would lessen the emission of nitrogen and sulfur in the environment.

- Public transportation, car pools and walking can reduce nitrogen, sulfur and lead emissions into the atmosphere.

- Sulfur and nitrogen are mostly released into the atmosphere from the burning of fossil fuels (e.g. Coal). Switching over to alternative forms of energy such as geothermal, water, wind, and solar power would help to a great extent. All the above measures are simple steps that can easily be adopted on an individual level. Acid rain has become an international issue because of its serious and definite danger to life on earth. Many international treaties have been signed i.e. the Sulfur Emissions Reduction Protocol and the Convention on Long-Range Transboundary Air Pollution. Installing Flue Gas Desulfurization e.g. wet scrubber in coal-burning power plants to remove sulfur-containing gases - is one of the steps taken by the USA, and is followed by a number of developed and developing countries.

\section{Neutranzing Acid Rain:}

Acid rain can be neutralized by reaction with calcium $(\mathrm{Ca})$ and magnesium $(\mathrm{Mg})$ compounds in soil. Limestone $\left(\mathrm{CaCO}_{3}\right)$. A substance common in soil, neutralizes acids when $\mathrm{H}^{+}$ions replace calcium-producing $\mathrm{Ca}^{2+}$ ions. Deep soils rich in metallic compounds have a greater capacity to neutralize acid rain than shallow soil or soil composed of non-metals do. If the acid rain is not neutralized, the acid percolates into the ground or flows into lakes and streams. Changes in the $\mathrm{pH}$ of water have damaging effects on aquatic life, including micro organisms, plants and animals living in the lakes. All aquatic organisms have $\mathrm{pH}$ tolerance of range they live within in table Tabale-2.They can soon die in water outside their tolerance. Some organisms appear to be more tolerant of acidic environments than others, and some adult organisms may be more tolerant than their eggs and embryos.

\section{Conclusion}

The ecological effects of acid rain are most clearly seen in the aquatic, or water, environments, such as streams, lakes, and marshes. Acid rain flows into streams, lakes, and marshes after falling on forests, fields, buildings, and roads. Acid rain also falls directly on aquatic habitats. Acid rain affects each and every components of ecosystem. Acid rain also damages man-made materials and structures Acid rain is one of the most serious environmental problems emerged due to air pollution Sulphur dioxide (SO2) and oxides of nitrogen and ozone to some extent are the primary causes of acid rain. These pollutants originate from human activities such as combustion of burnable waste, fossil fuels in thermal power plants and automobiles. These constituents interact with reactants present in the atmosphere and result into acid deposition Due to the interaction of these acids with other constituents of the atmosphere, protons are released causing increase in the soil acidity, lowering of soil $\mathrm{pH}$ mobilizes and leaches away nutrient cations and increases availability of toxic heavy metals As acid rain flows through soils in a watershed, aluminum is released from soils into the lakes and streams located in that watershed. So, as pH in a lake or stream decreases, aluminum levels increase. Both low 
$\mathrm{pH}$ and increased aluminum levels are directly toxic to fish. In addition, low pH and increased aluminum levels cause chronic stress that may not kill individual fish, but leads to lower body weight and smaller size and makes fish less able to compete for food and habitat. Acid rain causes a cascade of effects that harm or kill individual fish, reduce fish population numbers, completely eliminate fish species from a water body, and decrease biodiversity. These mobilized contaminants are dissolved in soil and water make their way to groundwater that is drunk by humans and contaminate the food (Fish, meat, and vegetables) eaten by humans. These heavy metals get accumulated in the body and resulted into various health problems like dry coughs, asthma, headache, eye, nose and throat irritations.

\section{References}

[1]. Acid Rain in New England, A Brief History. Epa.gov. Retrieved on 2013-02-09.

[2] Likens, G. E., Bormann, F. H. and Johnson, N. M. (1972). "Acid rain". Environment 14 (2) 33-40. doi:10.1080/00139157.1972.9933001

[3]. E. S. de Beer, ed. The Diary of John Evelyn, III, 1955 (19 September 1667) p. 495.

[4]. Glossary, United States: NASA Earth Observatory, acid rain, archived from the original on 2011-12-13, retrieved 2013-02-15

[5]. Weathers, K. C. and Likens, G. E. (2006). "Acid rain", pp. 1549-1561 in: W. N. Rom and S. Markowitz (eds.). Environmental and Occupational Medicine. Lippincott-Raven Publ., Philadelphia. Fourth Edition, ISBN 0781762995.

[6]. Seinfeld, John H.; Pandis, Spyros N (1998). Atmospheric Chemistry and Physics — From Air Pollution to Climate Change. John Wiley and Sons, Inc. ISBN 978-0-471-17816-3

[7]. Likens, G. E. and Bormann, F. H. (1974). "Acid Rain: A Serious Regional Environmental Problem". Science 184 (4142): $1176-9$. doi:10.1126/science.184.4142.1176. PMID 17756304.

[8]. Keller, C. K.; White, T. M.; O'Brien, R.; Smith, J. L. (2006). "Soil CO2 dynamics and fluxes as affected by tree harvest in an experimental sand ecosystem". Journal of Geophysical Research 111. doi:10.1029/2005JG000157.

[9] . Tripathi, A.K. and Mukesh Gautam. (2007) Biochemical parameters of plants as indicators of air pollution. J. Environ. Biol., 28, 127-132.

[10]. Dwivedi, A.K. and B.D. Tripathi. (2007). Pollution tolerance and distribution pattern of plants in surrounding area of coal-fired industries. J. Environ. Biol., 28, 257-263.

[11]. Galloway, JN; Dianwu, Z; Jiling, X; Likens, GE (1987). "Acid rain: China, United State and a remote area". Science 236 (4808): 1559-62. doi:10.1126/science.236.4808.1559. PMID 17835740.

[12]. Chandru (2006-09-09). "CHINA: Industrialization pollutes its country side with Acid Rain". Southasiaanalysis.org. Retrieved 201011-18.

[13]. Lefohn, A.S.; Husar, J.D.; Husar, R.B. (1999), Global Sulfur Emissions Database, United States: A.S.L. \& Associates

[14]. Likens, G. E., Wright, R. F.; Galloway, J. N. and Butler, T. J. (1979). "Acid rain". Scientific American 241 (4): $43-51$. doi:10.1038/scientificamerican1079-43.

[15]. Likens, G. E. (1984). "Acid rain: the smokestack is the "smoking gun"'". Garden 8 (4): $12-18$.

[16]. Rennenberg H, Gessler A (2001) Acid rain. Nature encyclopedia of life sciences. Nature Publishing Group, London

[17]. Baedecker, P.A., M.M. Reddy, K.J Reimann and C.A. Sciammarella.(1992) Effects of acidic deposition on the erosion of carbonate stone experimental results from the United States national acid precipitation assessment program (NAPAP). Atmos. Environ., 263, $147-158$.

[18]. "UK National Air Quality Archive: Air Pollution Glossary". Airquality.co.uk. 2002-04-01. Retrieved 2010-11-18.

[19]. Okochi H., H.Kameda, Hasegawa, N.Saito,K.,Kubota anM.Lgawa:Deterioration of concrete structures by acid depositionAassessement of the role of acid rain on deterioration by laboratory and field exposure experiments using mortar specimens.Atoms.Environ.,95,419-424 (1982).

[20]. Sersale, R., G. Frigione and L. Bonavita (1998). Acid deposition and concrete attack: main influence. Cement and Concrete Research, 28, 19-24.

[21]. Dutt,(1984) . Delhi gasps for its air. Mazingira, 8, 10-11 (1984)

[22]. DeHayes, D.H., Schaberg, P.G. and G.R. Strimbeck. (2001). Red Spruce Hardiness and Freezing Injury Susceptibility. In: F. Bigras, ed. Conifer Cold Hardiness. Kluwer Academic Publishers, the Netherlands ISBN 0792366360.

[23]. Lazarus, Brynne E.; Schaberg, Paul G.; Hawley, Gary J.; DeHayes, Donald H. (2006). "Landscape-scale spatial patterns of winter injury to red spruce foliage in a year of heavy region-wide injury". Can. J. For. Res. 36: 142-152. doi:10.1139/x05-236. highbeam copy

[24]. Likens, G.E.; Driscoll, C.T.; Buso, D.C.; Mitchell, M.J.; Lovett, G.M.; Bailey, S.W.; Siccama, T.G.; Reiners, W.A.; Alewell, C. (2002). "The biogeochemistry of sulfur at Hubbard Brook". Biogeochemistry 60 (3): 235. doi:10.1023/A:1020972100496.

[25]. Likens, G. E.; Driscoll, C. T.; Buso, D. C. (1996). "Long-Term Effects of Acid Rain: Response and Recovery of a Forest Ecosystem". Science 272 (5259): 244. doi:10.1126/science.272.5259.244.

[26]. Rodhe, H., et al. The global distribution of acidifying wet deposition. Environmental Science and Technology. vlo. 36, no. 20 (October) p. $4382-8$

[27]. US EPA: Effects of Acid Rain - Forests

[28]. Effects of Acid Rain - Human Health. Epa.gov (2006-06-02). Retrieved on 2013-02-09.

[29]. Lynn, D(1976). Air Pollution: Threat and response, Addison Wesley, Reading, MA, USA .

[30]. Okita,T. (1983). Acid precipitation and related phenomena in Japan. Water Quality Bulletin 8,101- 108. 